4 Thomas Rydzak ${ }^{1,2}$, David Garcia ${ }^{1,2}$, David M. Stevenson ${ }^{3}$, Margaret Sladek ${ }^{1,2}$, Dawn 5

\section{Deletion of Type I glutamine synthetase deregulates nitrogen metabolism and increases ethanol production in Clostridium thermocellum} M. Klingeman ${ }^{1,2}$, Evert K. Holwerda ${ }^{1,4}$, Daniel Amador-Noguez ${ }^{3}$, Steven D. Brown $^{1,2}$, and Adam M. Guss ${ }^{1,2 *}$

${ }^{1}$ Biosciences Division, Oak Ridge National Laboratory, Oak Ridge, Tennessee, United States of America

${ }^{2}$ BioEnergy Science Center, Oak Ridge National Laboratory, Oak Ridge, Tennessee, United States of America

${ }^{3}$ Department of Bacteriology, University of Wisconsin-Madison, Madison, Wisconsin, United States of America

${ }^{4}$ Thayer School of Engineering at Dartmouth College, Hanover, New Hampshire, United States of America

*Correspondence should be addressed to A.M.G: One Bethel Valley Road, Oak Ridge, TN 37831-6038 USA. Fax: + 1-865-576-8646. Email: gussam@ornl.gov

This manuscript has been authored by UT-Battelle, LLC under Contract No. DEAC05-00OR22725 with the U.S. Department of Energy. The United States

Government retains and the publisher, by accepting the article for publication, acknowledges that the United States Government retains a non-exclusive, paid-up, irrevocable, world-wide license to publish or reproduce the published form of this manuscript, or allow others to do so, for United States Government purposes. The Department of Energy will provide public access to these results of federally 
26 sponsored research in accordance with the DOE Public Access Plan

27 (http://energy.gov/downloads/doe-public-access-plan). 


\section{Abstract}

29 Clostridium thermocellum rapidly deconstructs cellulose and ferments resulting

30 hydrolysis products into ethanol and other products, and is thus a promising

31 platform organism for the development of cellulosic biofuel production via

32 consolidated bioprocessing. While recent metabolic engineering strategies have

33 targeted eliminating canonical fermentation products (acetate, lactate, formate, and

$\left.34 \mathrm{H}_{2}\right)$, C. thermocellum also secretes amino acids, which has limited ethanol yields in

35 engineered strains to approximately $70 \%$ of the theoretical maximum. To investigate

36 approaches to decrease amino acid secretion, we attempted to reduce ammonium

37 assimilation by deleting the Type I glutamine synthetase $(g \ln A)$ in an essentially

38 wild type strain of $C$. thermocellum. Deletion of $g \ln A$ reduced levels of secreted

39 valine and total amino acids by $53 \%$ and $44 \%$ respectively, and increased ethanol

40 yields by 53\%. RNA-seq analysis revealed that genes encoding the RNF-complex

41 were more highly expressed in $\Delta g \ln A$ and may have a role in improving NADH-

42 availability for ethanol production. While a significant up-regulation of genes

43 involved in nitrogen assimilation and urea uptake suggested that deletion of $g \ln A$

44 induces a nitrogen starvation response, metabolomic analysis showed an increase in

45 intracellular glutamine levels indicative of nitrogen-rich conditions. We propose

46 that deletion of $g \ln A$ causes deregulation of nitrogen metabolism, leading to

47 overexpression of nitrogen metabolism genes and, in turn, elevated glutamine

48 levels. Here we demonstrate that perturbation of nitrogen assimilation is a

49 promising strategy to redirect flux from the production of nitrogenous compounds

50 toward biofuels in C. thermocellum. 
52 Key Words: Cellulosic ethanol, Clostridium thermocellum, glutamine synthetase,

53 amino acid secretion

\section{1. Introduction}

56 Increasing global energy demands, depletion of low extraction-cost fossil fuel

57 reserves, and environmental concerns are driving forces for the search for renewable

58 and environmentally friendly energy sources. Bioethanol is among the leading

59 alternatives to petroleum-derived fossil fuels for the transportation sector given that

60 it is compatible with current engine technologies, burns cleaner than gasoline, has a

61 high octane/cetane number, and can be derived from renewable biomass feedstocks

62 (Arora et al., 2015; Vohra et al., 2014). The USA and Brazil are among the leaders

63 in ethanol production, generating 14.8 and 7.1 billions of gallons of ethanol in 2015,

64 respectively (RFA, 2016). Of the total global bioethanol produced, roughly $50 \%$ is

65 derived from maize and $30 \%$ is derived from sugarcane (DEFRA, 2008). This

66 dependence of bioethanol production on food/feed crops may increase food costs

67 and volatility of ethanol prices (Vohra et al., 2014). Life cycle analysis has further

68 shown that substituting gasoline with cellulosic ethanol can reduced greenhouse gas

69 emission by up to $115 \%$, versus a 19-48\% reduction with corn ethanol (Wang et al.,

70 2012). While the 2005 USA Energy Policy Act mandates an increase of biofuel

71 production from 22 to 36 billion gallons per year by 2022, the cap on starch-derived

72 ethanol is to remain at 15 billion gallons per year (RFA, 2016). Thus, a transition to

73 lignocellulosic feedstocks for bioethanol production is needed. 
75 Currently, bioethanol is predominantly made via fermentation of mono- or

76 disaccharides using Saccharomyces cerevisiae or Zymomonas mobilis. While these

77 organisms are capable of high ethanol yields and titers, they cannot natively

78 deconstruct highly recalcitrant lignocellulosic biomass to liberate fermentable sugars

79 (Himmel et al., 2007). Thus, lignocellulosic bioethanol production using these

80 organisms requires chemical and/or enzymatic hydrolysis of lignocellulosic

81 biomass, separate cellulase production, and subsequent fermentation, increasing

82 production costs. Alternatively, a number of organisms are capable of cellulase-

83 mediated cellulose hydrolysis and subsequent fermentation to ethanol via

84 consolidated bioprocessing (CBP), potentially allowing for enhanced process

85 economics (Lynd et al., 2005; Lynd et al., 2002). However, to date, no stand-alone

86 process can produce ethanol from lignocellulose at yields and titers sufficient for

87 economic viability.

89 Clostridium thermocellum is a promising candidate for lignocellulosic bioethanol

90 production via CBP because it has the innate ability to rapidly solubilize raw

91 biomass with minimal or no pre-treatment (Paye et al., 2015), and ferment resulting

92 cellulosic hydrolysis products into ethanol. However, due to branched product

93 pathways that divert carbon and electrons to products other than ethanol, wild type

94 C. thermocellum ethanol yields are approximately $30 \%$ of the theoretical maximum

95 of 2 moles ethanol per mole hexose, well below industrial requirement of at least

$9690 \%$. In addition to canonical fermentation products (acetate, lactate, formate, and

$97 \mathrm{H}_{2}$ ), secreted amino acids (primarily valine and alanine) (Ellis et al., 2012; 
98 Kridelbaugh et al., 2013; van der Veen et al., 2013) and other compounds including

99 pyruvate, malate, fumarate, isobutanol, and butanediol (Holwerda et al., 2014),

100 further limit ethanol yields. Metabolic pathways have been elucidated via

101 enzymology (Carere et al., 2014; Lamed and Zeikus, 1980; Lin et al., 1998; Rydzak

102 et al., 2009; Sparling et al., 2006; Taillefer et al., 2015; Zhou et al., 2013),

103 transcriptomics (Carere et al., 2014; Deng et al., 2013; Raman et al., 2011; Wilson et

104 al., 2013; Yang et al., 2012), proteomics (Raman et al., 2009; Rydzak et al., 2014;

105 Rydzak et al., 2012), and genetics (Argyros et al., 2011; Biswas et al., 2014; Biswas

106 et al., 2015; Deng et al., 2013; Tripathi et al., 2010). Furthermore, improvements in

107 C. thermocellum electrotransformation protocols (Olson and Lynd, 2012; Tyurin et

108 al., 2004), transformation efficiencies (Guss et al., 2012), genetic modification

109 methods (Argyros et al., 2011; Mohr et al., 2013; Tripathi et al., 2010), and tools for

110 heterologous expression (Groom et al., 2016; Olson et al., 2015) have allowed for

111 rational metabolic engineering of $C$. thermocellum to improve ethanol yields by

112 eliminating competing pathways and expressing heterologous ones. While deletion

113 of phosphotransacetlylase (pta) (Tripathi et al., 2010) and pyruvate:formate lyase

114 (pfl) (Rydzak et al., 2015) eliminated acetate and formate production, respectively,

115 marginal impacts on ethanol production were observed. Alternatively, elimination

116 of lactate, lactate and acetate, or $\mathrm{H}_{2}$ via deletion of lactate dehydrogenase (ldh)

117 (Biswas et al., 2014), ldh and pta (Argyros et al., 2011; van der Veen et al., 2013),

118 or [FeFe] hydrogenase maturation factor $(h y d G)$ and [NiFe] Ech-type hydrogenase

$119(e c h A-F)($ Biswas et al., 2015), respectively, improved ethanol production. While

120 stacking all of these deletions except $e c h A-F$ in a single strain $(\Delta h y d G \Delta l d h \Delta p f l$ 
121 Apta-ack; strain AG553) resulted in the highest ethanol yielding C. thermocellum

122 strain to date (Papanek et al., 2015), ethanol yields typically ranged from 50-70\% of

123 the theoretical maximum, which is still below the benchmark $96 \%$ ethanol yields

124 achieved by Saccharomyces cerevisiae or Zymomonas mobilis (Panesar et al., 2006).

125 Recently strain AG553 was evolved to grow faster, and the resulting strain was able

126 to produce $22 \mathrm{~g} / \mathrm{L}(478 \mathrm{mM})$ ethanol at $75 \%$ of the theoretical maximum yield on 60 $127 \mathrm{~g} / \mathrm{l}$ cellulose (Tian et al., 2016).

129 Recent studies have demonstrated that secreted amino acids typically account for 130 approximately $4-10 \%$ of total substrate consumed in wild type $C$. thermocellum, 131 reaching as high as $17 \%$ in certain mutants (i.e. evolved $\Delta l d h \Delta p t a$ strain), with 132 valine and alanine accounting for the bulk of these amino acids (Ellis et al., 2012;

133 Holwerda et al., 2014; Kridelbaugh et al., 2013; van der Veen et al., 2013). The 134 extent of amino acid secretion has also been shown to be dependent on medium 135 nitrogen content (Kridelbaugh et al., 2013) and carbon loading (Holwerda et al., 136 2014), and has been proposed to alleviate carbon and electron imbalances. While 137 few studies have measured amino acid secretion in other cellulolytic organisms, free 138 amino acids in Clostridium cellulolyticum fermentations have been reported to 139 account for $15 \%$ and $6 \%$ of total carbon consumed on cellobiose and cellulose, 140 respectively (Desvaux et al., 2001a; Desvaux et al., 2001b; Desvaux et al., 2001c; 141 Guedon et al., 1999), demonstrating that amino acid secretion in cellulolytic bacteria 142 is not exclusive to C. thermocellum. In C. cellulolyticum, 30-fold higher 
143 protein/DNA ratios in supernatants versus cell extracts suggest that cell lysis is not

144 the cause of amino acids in the medium.

146 In most bacteria, ammonium assimilation typically occurs via glutamate

147 dehydrogenase (GLDH) or through the combination of glutamine synthetase (GS)

148 and glutamine-oxoglutarate aminotransferase/glutamate synthase (GOGAT).

149 GLDH catalyzes the reductive amination of $\alpha$-ketoglutarate to glutamate using

$150 \mathrm{NAD}(\mathrm{P}) \mathrm{H}$, typically under nitrogen-rich conditions (Shimizu, 2013). Alternatively,

151 under nitrogen-limited conditions, ATP-dependent GS aminates glutamate to

152 glutamine, and NAD $(\mathrm{P}) \mathrm{H}$ or ferredoxin-dependent GOGAT replenishes the

153 glutamate pool using glutamine and $\alpha$-ketoglutarate. GSs can be divided into three

154 groups which can be typically distinguished by amino acid length. These include

155 Type I GSs ( 360 aa) which are widely distributed among bacteria, Type II GSs

156 ( 450 aa) which are typically found in plants and some soil bacteria, and Type III

157 GSs ( 730 aa) which have been identified in anaerobic bacteria and cyanobacteria

158 (van Rooyen et al., 2011). While the structures and multimeric assembly of GSs

159 vary among these classes, differences in function, if any, still remains unclear.

160 With the exception of one study nearly three decades ago (Bogdahn and Kleiner,

161 1986), little has been done to elucidate nitrogen assimilation in C. thermocellum.

162 Enzyme activity studies showed high NADPH-dependent GLDH and moderate GS

163 activities, but failed to detect any NADH or NADPH-dependent GOGAT activity

164 (Bogdahn and Kleiner, 1986). Given that glutamate and glutamine are the primary 
165 source of assimilated nitrogen for the synthesis of amino acids, we hypothesized that

166 limiting the rate of nitrogen assimilation via glutamate and/or glutamine could

167 decrease total amino acid production, and in turn decrease levels of secreted amino

168 acids in $C$. thermocellum. Here, we deleted $g \ln A$ (Clo1313_2031) encoding the

169 Type I GS in an attempt to redirect carbon and electron flux away from amino acids

170 towards more canonical fermentation products including ethanol.

171

\section{2. Materials and Methods}

\section{2.1. Plasmid and strain construction}

174 All enzymes and reagents used for cloning were purchased from New England

175 Biolabs (Ipswich, MA), unless otherwise specified. Escherichia coli Top10 (dam ${ }^{+}$

$176 \mathrm{dcm}^{+}$; Invitrogen, Carlsbad, CA) and BL21 $\left(\mathrm{dam}^{+} \mathrm{dcm}\right.$; New England Biolabs,

177 Ipswitch, MA), used for plasmid construction and propagation, respectively, were

178 grown aerobically on LB medium supplemented with $12 \mu \mathrm{g} / \mathrm{ml}$ chloramphenicol as

179 required for plasmid maintenance. Plasmid isolation and purification was

180 performed using QIAprep spin miniprep kits (QIAGEN, Germantown, MD).

181 Plasmid pNJ22::2031_del for deletion of $g \ln A$ (Clo1313_2031) was constructed

182 using Gibson Assembly (Gibson 2009) according to the manufacturer's guidelines

183 using primers provided in Supplementary File 1. Briefly, fragments corresponding

184 to regions 500 bp upstream, downstream, and within the first $500 \mathrm{bp}$ of

185 Clo1313_2031 coding region, and a 1388 bp fragment encoding a chloramphenicol

186 acetyltransferase (cat) and a hypoxanthine phosphoribosyltransferase (hpt) driven by 
187 a C. thermocellum glyceraldehyde-3-phosphate (GapDH) promoter were amplified 188 using Phusion polymerase (New England Biolabs, Ipswich, MA). Resulting PCR

189 fragments were treated with DpnI to digest residual template DNA and were ligated 190 with EcoRV digested pNJ022 using Gibson assembly generating pNJ22::2031_del

191 (Supplementary File 2). Correct assembly of fragments was verified using 192 restriction digests and sequencing using primers provided in Supplementary File 1. 193 All plasmids used for C. thermocellum transformations were ultimately isolated 194 from E. coli dam ${ }^{+} d \mathrm{~cm}^{-}$BL21 (Guss et al., 2012).

Clostridium thermocellum DSM 1313 (Deutsche Sammlung von Microorganismen 197 und Zellkulturen, Braunshwieg, Germany) derivatized strains ( $\Delta h p t$ and $\Delta h p t \Delta g \ln A$ ) 198 were routinely grown anaerobically at $55^{\circ} \mathrm{C}$, unless otherwise specified, in a Coy 199 anaerobic chamber (Coy Laboratory Products, Grass Lake, MI) on 5 g/l cellobiose 200 in CTFUD medium (Rydzak et al., 2015). Medium was made anaerobic via 201 autoclaving to remove $\mathrm{O}_{2}$ from solution, followed by immediate transfer to the 202 anaerobic chamber to maintain anaerobicity. Medium was supplemented with 10 $203 \mu \mathrm{g} / \mathrm{ml}$ thiamphenicol, $50 \mu \mathrm{g} / \mathrm{ml}$ 5-fluoro-2'-deoxyuridine, or $500 \mu \mathrm{g} / \mathrm{ml} 8$ 204 azahypoxanthine (Tokyo Chemical Industry, Co., Tokyo, Japan) during $C$. 205 thermocellum strain construction when appropriate. All selection steps were 206 performed at $50^{\circ}$ C. C. thermocellum $\Delta h p t$ (Argyros et al., 2011) was transformed 207 via electroporation as previously described (Guss et al., 2012; Olson and Lynd, 208 2012). This strain allows the hpt gene to be used as a counter-selectable marker to 209 enable gene deletion. The $g \ln A$ gene was deleted as previously described (Argyros 
210 et al., 2011; Olson and Lynd, 2012) using plasmid pNJ22::2031_del. Gene deletion

211 was confirmed using primer sets provided in Supplementary File 1 as shown in

212 Supplementary File 3. Deletion of $g \ln A$ was further confirmed via whole genome

213 resequencing and RNA-seq analysis (discussed below). Culture purity was

214 routinely confirmed via $16 \mathrm{~S}$ sequencing. This resulted in strain AG1329 (C.

215 thermocellum $\Delta h p t \Delta g \ln A$ ). This whole process was repeated to delete $g \ln A$ from $C$.

216 thermocellum $\Delta h p t$ a second time to recreate the strain to eliminate the possibility

217 that secondary mutations are responsible for the phenotype, resulting in strain

218 AG2070 (also C. thermocellum $\Delta h p t \Delta g \ln A$ ).

219

220 2.2. Fermentation conditions

221 Fermentation experiments were performed at $55^{\circ} \mathrm{C}$ in sealed, nitrogen sparged Balch

222 tubes (27 ml; Belco Glass Inc., Vineland, NJ) containing $10 \mathrm{ml}$ of $\mathrm{MTC}_{5}$ medium

223 supplemented with $4.5 \mathrm{~g} / \mathrm{l}$ cellobiose as previously described (Rydzak et al., 2015).

224 Tubes were inoculated with $2 \%$ exponential phase $\left(\mathrm{OD}_{600} \sim 0.4\right)$ cultures grown on

$225 \mathrm{MTC}_{5}$. Final fermentation product, amino acid, biomass, and $\mathrm{pH}$ measurements

226 were taken following complete cellobiose utilization ( $<1.0 \mathrm{mM}$ remaining).

227 Fermentations were performed a minimum of three times with three independent

228 biological replicates each time. Samples for RNA-seq and metabolomic analysis

229 were grown at $55^{\circ} \mathrm{C}$ in sealed, nitrogen sparged $162 \mathrm{ml}$ serum bottles containing 50

$230 \mathrm{ml}$ of $\mathrm{MTC}_{5}$ supplemented with $4.5 \mathrm{~g} / \mathrm{l}$ cellobiose. Samples were harvested in early

231 exponential phase $\left(\mathrm{OD}_{600} \sim 0.33\right)$ and analysis was performed in quadruplicate for

232 each strain. To monitor growth rates, cells were grown in 48 well microtiter plates 
233 in quadruplicate (Corning, Tewksbury, MA) containing $600 \mu \mathrm{MTC}_{5}$ in an Eon

234 Microplate Spectrophotometer (BioTek Instruments Inc., Winooski, VT) situated in

235 a Coy anaerobic chamber. All chemicals were reagent grade and obtained from

236 Sigma-Aldrich (St. Louis, MO) or Fisher Scientific (Waltham, MA) unless

237 otherwise specified.

239 2.3. Analytical measurements

240 Cell growth was monitored spectrophotometrically at $\mathrm{OD}_{600}$ in an Eon Microplate

241 Spectrophotometer (BioTek Instruments Inc., Winooski, VT). Cellobiose, glucose,

242 and fermentation products (pyruvate, lactate, acetate, formate, ethanol) were

243 analyzed using a Breeze High Performance Liquid Chromatography system (Waters,

244 Milford, MA) using an Aminex-HPX-87H column (Bio-Rad, Hercules, CA) with a

$2455 \mathrm{mM}$ sulfuric acid mobile phase. $\mathrm{H}_{2}$ was measured using an Agilent Technologies

2466850 Series II Gas Chromatograph (Agilent Technologies, Santa Clara, CA) using a

247 thermoconductivity detector set at $190^{\circ} \mathrm{C}$ with a $\mathrm{N}_{2}$ reference flow and a Carbonex

2481010 PLOT (30.0 m $\times 530 \mu$ I.D.; model Supelco 25467) column. Secreted amino

249 acids were measured using an Aracus Amino Acid Analyzer (membraPure, Berlin,

250 Germany) using a T111 Li-cation exchange column with eluents supplied by the

251 manufacturer. Ninhydrin derived amino acids were measured photometrically at

$252570 \mathrm{~nm}$ with the exception of proline, which was measured at $440 \mathrm{~nm}$. Final $\mathrm{pH}$

253 was measured using an Accument AB15 Basic pH meter (Fisher Scientific;

254 Pittsburg, PA) at room temperature and in room atmosphere. Total nitrogen and

255 carbon in cell pellets was were determined using a Simadzu TOC-Vcph Total 
256 Organic Carbon analyzer with added Total Nitrogen unit and a ASI-V autosampler

257 (Shimadzu Scientific Instruments, Columbia, MD) with an Avicel and glycine

258 standards for carbon and nitrogen determination, respectively (Holwerda et al., 259 2012).

260

261 2.4. Whole genome resequencing

262 Genome resequencing and analysis was performed by the DOE Joint Genome

263 Institute (JGI, Walnut Creek, CA) with an Illumina MiSeq instrument. Genomic

264 DNA was extracted using a Qiagen DNeasy kit (Qiagen, Valencia, CA). 100 ng of

265 DNA was sheared to $500 \mathrm{bp}$ fragments using the Covaris LE220 ultrasonicator

266 (Covaris) and size selected using AMPure XP SPRI beads (Beckman Coulter). The

267 fragments were treated with end-repair, A-tailing, and ligation of Illumina

268 compatible adapters (IDT, Inc) using the KAPA-Illumina library creation kit

269 (KAPA Biosystems). The prepared libraries were quantified using KAPA

270 Biosystem's next-generation sequencing library qPCR kit and run on a Roche

271 LightCycler 480 real-time PCR instrument. The quantified multiplexed libraries

272 were pooled in sets of 10, and sequenced on the Illumina MiSeq sequencer using an

273 indexed PE150 protocol with MiSeq V2 chemistry.

274

275 Paired-end reads were aligned to the reference genome [Genbank: CP002416] using 276 Burrows-Wheeler transform (Li and Durbin, 2009) and putative SNPs and small

277 indels were called using samtools and mpileup (Li et al., 2009). Putative structural

278 variants were called using a combination of BreakDancer (filtered to quality 90+) 
279 (Chen et al., 2009), and Pindel (Chen et al., 2009). Variants occurring in less than

$28090 \%$ of the reads and variants that were identical to those of the parent $\Delta h p t$ strain

281 (i.e., due to errors in the reference sequence) were filtered out. Raw data is available

282 from the JGI Sequence Read Archive (JGI Project Id: 1064732).

283

284 2.5. RNA isolation and ribosomal RNA removal

285 Pelleted cells, $50 \mathrm{~mL}$ from each sample, were resuspended in $1 \mathrm{~mL}$ of TRIzol

286 (Invitrogen, Carlsbad, CA, USA) and lysed by bead beating with $0.8 \mathrm{~g}$ of $0.1 \mathrm{~mm}$

287 glass beads (BioSpec Products, Bartlesville, OK, USA) for 3 x 20 seconds each at

$2886,500 \mathrm{rpm}$ in a Precellys 24 high-throughput tissue homogenizer (Bertin

289 Technologies, Montigny-le-Bretonneux, France). The RNA from each cell lysate

290 was purified, DNaseI-treated, and quantity and quality assessed, as previously

291 described (Yang et al., 2012). High quality total RNA (RIN>8) was depleted of

292 rRNA using Ribo-Zero rRNA Removal Kit for bacteria (Epicentre-Illumina, San

293 Diego, USA) following the manufacturer's protocol. The depleted sample was

294 purified on a RNA Clean \& Concentrator-5 (Zymo Research, Irvine, CA, USA)

295 following the manufacturer's protocol.

2.6. Library preparation and sequencing

297 Depleted RNA was used for RNA-Seq library preparation with the Epicentre

298 ScriptSeq v2 RNA-Seq Library Preparation Kit (Epicentre-Illumina, San Diego, CA,

299 USA) following the manufacturer's protocol (EPILIT329 Rev.C). Agencount

300 AMPure beads (Beckman Coulter, Indianapolis, USA) were used to purify the

301 cDNA, and unique indexes were added during 13 cycles of library amplification. 
302 The final RNA-Seq libraries were purified with Agencount AMPure beads

303 (Beckman Coulter, Indianapolis) and quantified with a Qubit fluorometer (Life

304 Technologies, Carlsbad, CA, USA). The library quality was assessed on a

305 Bioanalyzer DNA 7500 DNA Chip (Agilent, Santa Clara, CA, USA), and samples

306 were pooled and diluted. Sequencing was completed using a SR50 sequencing

307 protocol and V4 chemistry on an Illumina HiSeq 2500 platform (HudsonAlpha

308 Genomic Services Laboratory; Huntsville, AL).

2.7. RNA-Seq analysis

311 Raw reads were mapped to genome [GenBank:CP002416] using CLC Genomics

312 Workbench version 8.0 (CLC bio, Aarhus, Denmark) and the default settings for

313 prokaryote genomes. Counts of uniquely mapped reads were analyzed for

314 differential gene expression by DESeq2 (Love et al., 2014). Filtering was applied to

315 identify those genes with an FDR $<0.05$ and a greater than a $\log _{2}$ of $+/-1$ for

316 differential gene expression. Raw RNA-Seq data have been deposited in NCBI

317 Sequence Read Archive under accession SRP070709 and gene expression data

318 under NCBI GEO accession GSE78219.

320 2.8. Metabolite extraction and sample preparation for quantification

321 C. thermocellum intracellular metabolite extraction was performed anaerobically in

322 a Coy anaerobic chamber (Grass Lake, MI). Eight milliliters of culture (removed

323 with a $10 \mathrm{ml}$ syringe) was deposited by vacuum filtration onto a $0.2 \mu \mathrm{m}$ nylon

324 membrane (47 $\mathrm{mm}$ diameter). The membrane was then placed (cells down) into 1.5 
$325 \mathrm{ml}$ cold $\left(-20^{\circ} \mathrm{C}\right.$ or on dry ice) extraction solvent $(20: 20: 10 \mathrm{v} / \mathrm{v} / \mathrm{v}$ acetonitrile,

326 methanol, water) in a small petri disk and swirled. After a few moments the filter

327 was inverted (cells up) and solvent was passed over the surface of the membrane

328 several times to maximize extraction. Finally, the cell extract was stored at $-80^{\circ} \mathrm{C}$.

329 To measure extracellular metabolites, $2 \mathrm{ml}$ of media was collected by filtration 330 using a 0.22 um syringe filter and stored at $-80^{\circ} \mathrm{C}$.

332 Cell extracts from E. coli (K-12 substrain MG1655 rph $\left.{ }^{+} i l v G^{+}\right)$grown in ${ }^{13} \mathrm{C}$ 333 glucose were used as internal standards for quantitation of metabolites in $C$.

334 thermocellum strains. E. coli cells were grown aerobically to an $\mathrm{OD}_{600}$ of $\sim 0.45$ in 335 M9 minimal medium containing $0.4 \%$ universally labeled ${ }^{13} \mathrm{C}$-glucose as sole 336 carbon source. To assure complete labeling of metabolites in E. coli, inoculation 337 was performed using 1/50 dilution from an overnight culture that was also grown on

$338{ }^{13}$ C-labeled glucose. E. coli metabolites were extracted in a similar manner to the 339 procedure used for C. thermocellum (above), but under aerobic (benchtop) 340 conditions.

342 Extracellular metabolites were measured by empirically determining that 343 approximately $229 \mu \mathrm{l}$ of media was retained on the nylon membrane during the 344 metabolite extraction process. Therefore, this amount of filtered medium (from the 2 $345 \mathrm{ml}$ collected as above) was thawed and mixed with $1.5 \mathrm{ml}$ of extraction solvent. This 346 was then processed in parallel with the cellular samples as below. The volume of 
347 extracellular medium was found to be variable (probably dependent on co-deposited 348 cell volume) and so the exact amount was calculated (described below).

349 C. thermocellum and ${ }^{13} \mathrm{C}$-labeled E. coli extracts extracts were thawed, centrifuged 350 at 14,000 RPMs for 10 min to remove cell debris and the C. thermocellum 351 supernatants mixed with ${ }^{13}$ C-labeled $E$. coli supernatant in ratios of 1:5, 1:1, 5:1 and 352 1:0 (no ${ }^{13} \mathrm{C}$ labeled internal standards). These mixed samples were then fully dried 353 under a stream of nitrogen and subsequently re-suspended with solvent A (below) in 354 half the initial volume. Samples were then centrifuged to remove particulates, 355 transferred to HPLC vials, and analyzed by HPLC/MS.

357 Intracellular metabolite concentration for those metabolites with significant 358 extracellular presence were estimated by subtracting the extracellular from 359 intracellular values. To ensure accuracy glucose was used as an internal standard to 360 determine the exact amount of extracellular medium volume co-deposited with the 361 cells. This factor was then used to adjust the estimated concentration of extracellular 362 metabolites.

365 Samples were analyzed using an HPLC-MS/MS system consisting of a Dionex 366 UHPLC coupled by electrospray ionization (ESI; negative mode) to a hybrid 367 quadrupole - high-resolution mass spectrometer (Q Exactive orbitrap, Thermo 
368 Scientific) operated in full scan mode for detection of targeted compounds based on 369 their accurate masses and retention times (matched to purified standards). Liquid 370 chromatography (LC) separation was achieved using an ACQUITY UPLC® BEH $371 \mathrm{C} 18(2.1 \times 100 \mathrm{~mm}$ column, $1.7 \mu \mathrm{m}$ particle size $)$. Solvent A was 97:3 372 water:methanol with $10 \mathrm{mM}$ tributylamine (TBA) and approximately $9.8 \mathrm{mM}$ acetic 373 acid, $\mathrm{pH} \sim 8.2$; solvent $\mathrm{B}$ was $100 \%$ methanol. Total run time was 24.5 min with the 374 following gradient: 0 minutes, $5 \% \mathrm{~B} ; 2.5$ minutes, ramp from $5 \% \mathrm{~B}$ to $95 \% \mathrm{~B}$ over 37514.5 minutes; hold at $95 \%$ B for 2.5 minutes; return to $5 \%$ B over 0.5 minutes; hold 376 at 5\% B for 5 minutes. All samples were injected twice (analytical replicates). MS

377 scans consisted of full MS scanning for $\mathrm{m} / \mathrm{z}$ between $70-1000$ from time 0 to 18.5 378 minutes. Exceptions were: $\mathrm{m} / \mathrm{z}$ of 207-210 excluded between 2-3 min.; and m/z 190379192 excluded between 11-12 minutes. Metabolite peaks were identified using 380 Metabolomics Analysis and Visualization Engine (MAVEN) (Clasquin et al., 2012; 381 Melamud et al., 2010).

$384 \mathrm{CO}_{2}$ produced was calculated based on the expected equimolar ratio of $\mathrm{C}_{1}: \mathrm{C}_{2}$

385 compounds plus the additional $\mathrm{CO}_{2}$ liberated via valine biosynthesis, whereby $\mathrm{CO}_{2}$

$386=[($ ethanol + acetate + valine $)-($ formate $)]$ Ratios of oxidized to reduced

387 fermentation products $(\mathrm{O} / \mathrm{R})$ were calculated using reduction values of each

388 fermentation product, calculated as the number of oxygen atoms less one-half the

389 number of hydrogens in each compound (Moat et al., 2002). Carbon bound electron 
390 equivalents were calculated as described by Harris et al. (Harris and Adams, 1979)

391 and were used to determine electron recovery.

\section{3. Results}

394 3.1. Genomic analysis of nitrogen assimilation

395 The genome of C. thermocellum encodes one NADPH-dependent glutamate

396 dehydrogenase ( $g l d h$; Clo1313_1847), one cluster of glutamine-oxoglutarate

397 aminotransferase/glutamate synthase type enzymes (gogat; Clo1313_2032-2036),

398 and four glutamine synthetases, including three Type III glutamine synthetases

399 ( $g \ln N$; Clo1313_1357, 2038, 2303) approximately 700 amino acids in length, and

400 one 440 amino acid Type I glutamine synthetase ( $g \ln A$; Clo1313_2031) (Figure 1).

401 Biocyc (Karp, 2005; Romero and Karp, 2004) and DOOR (Dam et al., 2007; Mao et

402 al., 2009) predict Clo1313_2030-2036 to be a single operon, and the electron carrier

403 is unknown. Organization of genes and predicted operons involved in nitrogen

404 assimilation are provided in Supplementary File 4. In principle, any two of these

405 three enzymatic reactions (GLDH, GOGAT, and GS) should be sufficient to

406 assimilate $\mathrm{NH}_{4}{ }^{+}$, but the energetic cost differs depending on whether the ATP-

407 hydrolyzing GS is utilized. Clo1313_2030 is predicted to encode an ANTAR

408 domain protein/response regulator receiver (nitR) that is associated with regulation

409 of nitrogen metabolism. Ammonium is likely transported by Clo1313_2260, which

410 is an apparent fusion protein of an ammonium transporter (AmtB) with the

411 regulatory protein $\mathrm{GlnK}$ (also called $\mathrm{P}_{\mathrm{II}}$ ). Urea is known to be a nitrogen source for

412 C. thermocellum, and it encodes a urease gene cluster, including genes encoding the 
413 urease enzyme (Clo1313_2490-2492), urease maturation genes (Clo1313_2486-

414 2488), and a urea transporter (Clo1313_2493-2497). C. thermocellum also encodes

415 putative nitrogenase subunits nifD, nifK, and nifH (Clo1313_2331, 2332, and 2339,

416 respectively); however, nitrogenase activity has not been detected and $\mathrm{N}_{2}$ does not

417 seem to serve as a nitrogen source (Bogdahn and Kleiner, 1986; Kridelbaugh et al.,

418 2013).

419

Glycolysis

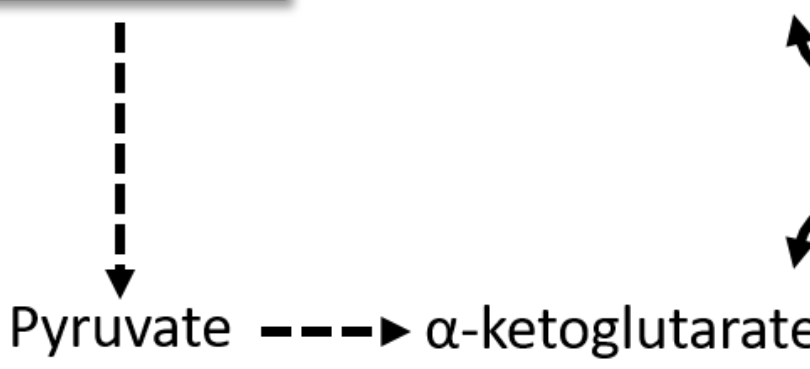

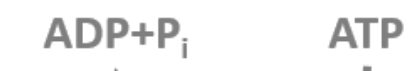

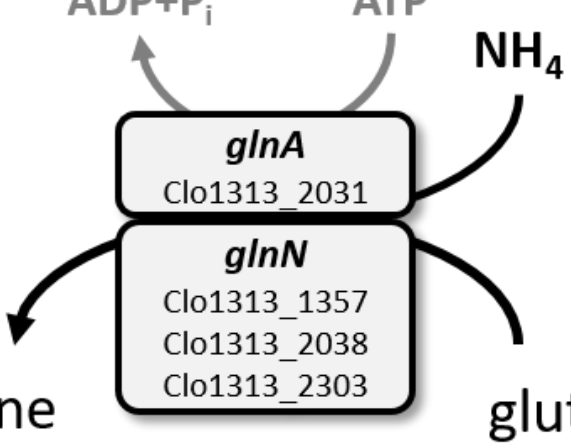

glutamate

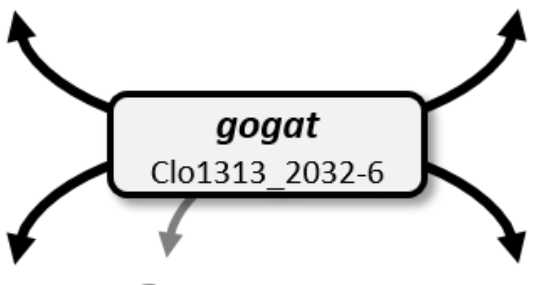

$2 \mathrm{e}^{-}$

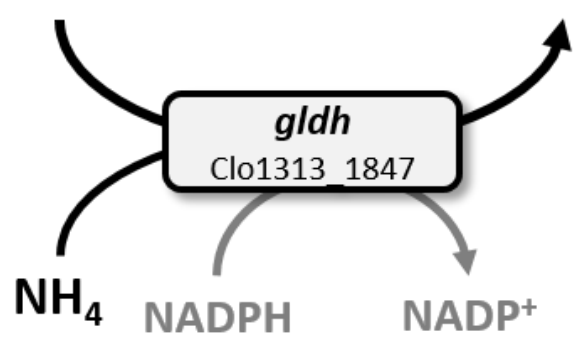

420

421

422

423

424

425

426
Figure 1: Nitrogen assimilation pathway in $C$. thermocellum based on genome annotation. $g \ln A$, Type I glutamine synthetase; $g \ln N$, Type III glutamine synthetase; gogat, glutamine-oxoglutarate aminotransferase/glutamate synthase type enzymes; gldh, glutamate dehydrogenase. Dashed lines indicate multiple enzymatic steps. 
428 increases ethanol production

429 Glutamine synthetases allow for high efficiency $\mathrm{NH}_{4}{ }^{+}$uptake by coupling

430 assimilation to ATP hydrolysis, providing a thermodynamic driving force. GlnA is

431 the most highly expressed glutamine synthetase in C. thermocellum (Gowen and

432 Fong, 2010; Wilson et al., 2013), and it is also the only Type I enzyme, which can

433 have both catalytic and regulatory functions. Therefore, the $g \ln A$ gene,

434 Clo1313_2031, was deleted in C. thermocellum $\Delta h p t$, resulting in strain $\Delta h p t \Delta g \ln A$,

435 which will be referred to as $\Delta g \ln A$. C. thermocellum $\Delta h p t$ (Argyros et al., 2011)

436 was used as the parent strain given that its growth and product profiles were the

437 same as the wild type DSM1313 strain and allowed for a selection method for our

438 deletion process. C. thermocellum $\Delta h p t$ and $\Delta g \ln A$ were grown on $4.5 \mathrm{~g} / 1$ (13.1

$439 \mathrm{mM})$ cellobiose in defined medium $\left(\mathrm{MTC}_{5}\right)$. Deletion of $g \ln A$ had no impact on

440 growth, as both $\Delta h p t$ and $\Delta g \ln A$ strains grew to a final $\mathrm{OD}_{600}$ of $\sim 0.88$ and had a

441 mid-exponential phase generation time of $1.3 \mathrm{~h}( \pm 0.1)$ (Supplementary File 5a).

442 Total elemental carbon in cell pellets for $\Delta h p t$ and $\Delta g \ln A$ was $0.252( \pm 0.010)$ and

$4430.269 \mathrm{~g} / \mathrm{l}( \pm 0.017)$, respectively (corresponding to 21.0 and $22.4 \mathrm{mM}$ of carbon,

444 respectively), and total pellet nitrogen was $0.062( \pm 0.001)$ and $0.069(0.002) \mathrm{g} / \mathrm{l}$,

445 respectively, further demonstrating that deletion of $g \ln A$ had no significant impact

446 on microbial biomass production. Interestingly, the initial $\mathrm{pH}$ of $\mathrm{MTC}_{5}(\mathrm{pH}=7.43 \pm$

4470.06 ) decreased to only $6.64 \pm 0.13$ in $\Delta g \ln A$ cultures versus $5.86 \pm 0.16$ in $\Delta h p t$

448 cultures. 
450 Fermentation products were measured following near-completion of cellobiose

451 utilization (<1.0 mM remaining), approximately 10 hours after peak OD was

452 reached. Deletion of $g \ln A$ increased ethanol production by 53\%, improving ethanol

453 yields from 0.86 to 1.22 moles per mole hexose equivalent (Figure 2a, Table 1,

454 Supplementary File 5b). While negligible changes in formate, acetate, and

455 extracellular pyruvate were observed, lactate production was nearly completely

456 abolished and $\mathrm{H}_{2}$ production decreased by $38 \%$. Furthermore, total amino acid

457 secretion decreased by $44 \%$, with the most abundant secreted amino acids, valine

458 and alanine, decreasing by $53 \%$ and $46 \%$, respectively (Figure 2b). Conversely,

459 carbon and electron recoveries from canonical fermentation products and biomass

460 increased by $9.5 \%$ and $8.6 \%$, respectively, in $\Delta g \ln A$ fermentations (Table 1),

461 demonstrating that additional carbon and electron flux is diverted from secreted

462 amino acids to canonical fermentation products. While total carbon and electron

463 recoveries were both c.a. $100 \%$ in $\Delta g \ln A$ fermentations, recoveries were $4.3 \%$ and

$464 \quad 4.9 \%$ lower, respectively, in $\Delta h p t$ fermentations, suggesting that some products may

465 be unaccounted for in the latter.

466 A) 

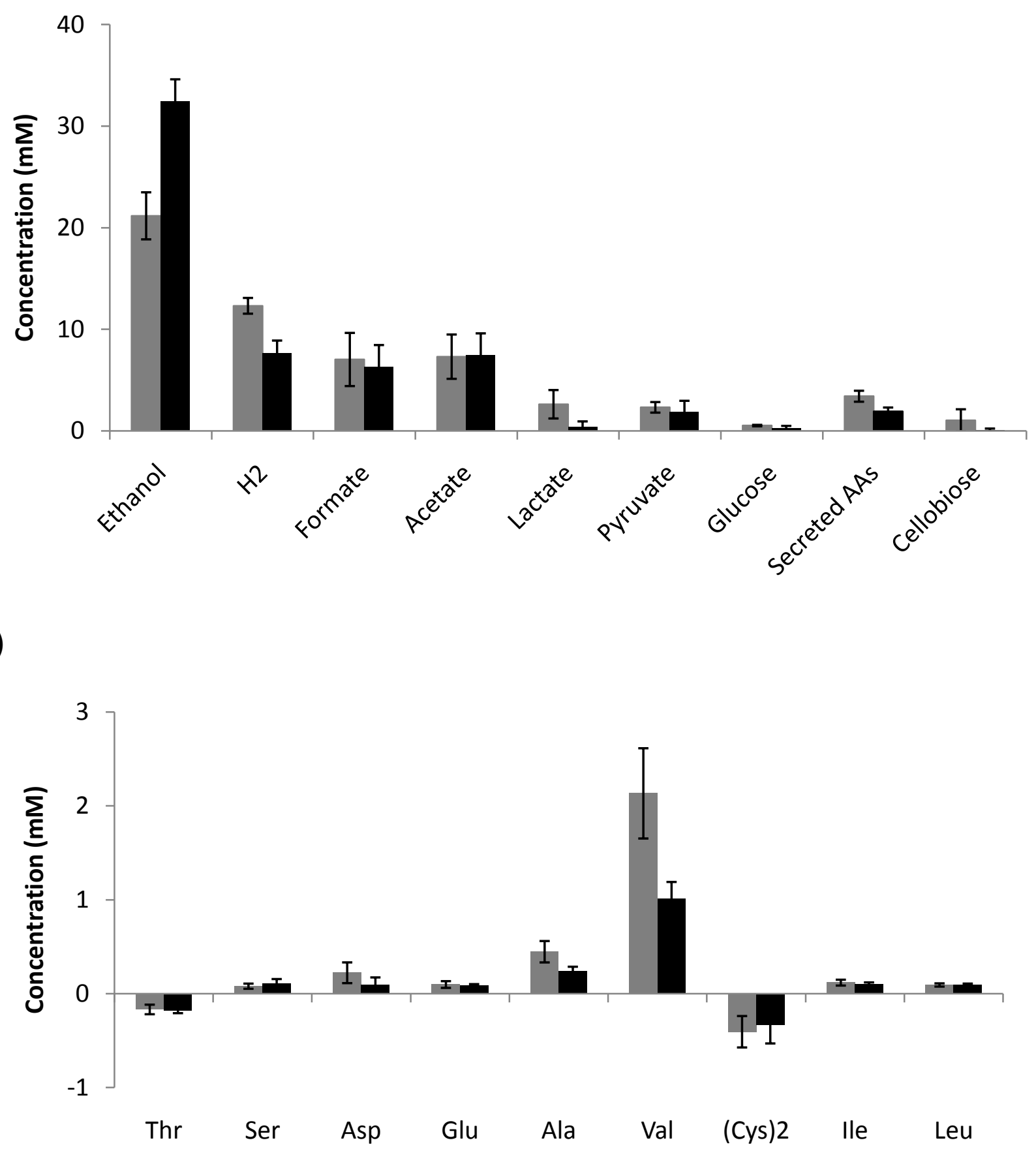

470 Figure 2. Final fermentation products (A) and secreted amino acids (B) of $C$.

471 thermocellum strains. All products were measured upon completion of cellobiose

472 utilization. Grey bars, $\Delta h p t$; black bars, $\Delta g \ln A$; (Cys)2, cystine. Only amino acids

473 with a change of greater than $0.08 \mathrm{mM}$ compared to $\mathrm{MTC}_{5}$ medium are shown.

474 Only total secreted amino acid values are presented in Figure 2A. Negative values

475 in Figure 2B indicate consumption of amino acids from the growth medium. 
477 Table 1. Final product yields and fermentation balances of $\Delta h p t$ and $\Delta g \ln A$ on $4.5 \mathrm{~g} / \mathrm{l}$ cellobiose in batch cultures

478 grown in MTC $_{5}$. Carbon recoveries of canonical fermentation products including biomass carbon (FPs), secreted amino 479 acids (AAs), and total secreted products are provided.

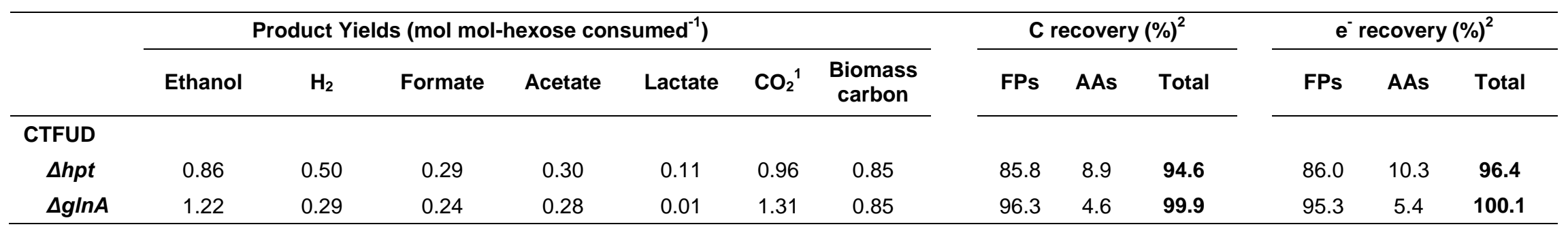

480

$481{ }^{1} \mathrm{CO}_{2}$ was calculated using $\mathrm{C} 1$ :C2 ratio using ethanol, acetate, valine and formate concentrations.

$482{ }^{2}$ Carbon and electron recoveries were calculated based on substrate (cellobiose), canonical end-product (ethanol, $\mathrm{H}_{2}$,

483 formate, acetate, lactate, pyruvate, glucose), secreted amino acid, and elemental carbon biomass measurements, and

484 calculated $\mathrm{CO}_{2}$ (from $\mathrm{C}_{1}: \mathrm{C}_{2}$ ratio). 
486 phenotype

487 During strain construction, unintended mutations can be fixed in the population due 488 to the single colony purification steps. While most of these mutations do not result 489 in a noticeable phenotype, it was possible that unintended mutations were 490 responsible for increased ethanol production in $\Delta g \ln A$. Therefore, the mutant strain 491 was resequenced and compared to the parent strain. A total of 7 high-confidence 492 mutations were found in $\Delta g \ln A$ (Table 2). As expected, resequencing analysis 493 identified the deletion of $g \ln A$. Three genes in $\Delta g \ln A$ had non-synonymous 494 mutations. These included genes encoding (i) a family 18 glycoside hydrolase 495 predicted by KOG and CAZy to be a chitinase, (ii) a protein of unknown function, 496 and (iii) a hemerythrin-like metal-binding protein found upstream of chemotaxis 497 protein CheC. One 35 bp deletion was identified upstream and within the coding 498 region of a putative methyl-accepting chemotaxis sensory transducer, eliminating 499 the ribosome binding site and ATG start codon. Two other mutations were found in 500 intergenic regions (Table 2) that could have altered expression of the adjacent genes. 501 RNAseq analysis (see below) revealed that only expression of the hypothetical 502 protein Clo1313_1767 was affected (increased 4-fold). 
Table 2. High confidence mutations found in $\Delta g \ln A$ that are not found in the parent $\Delta h p t$ strain. INS, insertion; DEL, deletion. Changes in amino acids within coding region mutations are indicated

\begin{tabular}{|c|c|c|c|c|c|c|}
\hline \multicolumn{2}{|l|}{ Position } & \multirow[t]{2}{*}{ Strand } & \multirow[t]{2}{*}{ Region } & \multirow[t]{2}{*}{ Locus tags } & \multirow[t]{2}{*}{ Genes } & \multirow[t]{2}{*}{ Type } \\
\hline Start & Stop & & & & & \\
\hline 2395922 & 2397259 & - & CODING & Clo1313 2031 & glutamine synthetase, type I $(g \ln A)$ & DEL \\
\hline 491357 & 491357 & + & CODING & Clo1313_0436 & glycoside hydrolase family 18 & W258R \\
\hline 2327020 & 2327020 & - & CODING & Clo1313_1979 & protein of unknown function UPF0027 & D360E \\
\hline 3494201 & 3494201 & + & CODING & Clo1313_2980 & hemerythrin-like metal-binding protein & V45E \\
\hline 2131552 & 2131586 & - & $\begin{array}{l}\text { CODING/ } \\
\text { INTERGENIC }\end{array}$ & Clo1313_1820 & $\begin{array}{l}\text { methyl-accepting chemotaxis sensory } \\
\text { transducer }\end{array}$ & DEL \\
\hline 1728952 & 1728952 & + & INTERGENIC & $\begin{array}{l}\text { Clo1313_1476 (up) } \\
\text { Clo1313_1477 (down) }\end{array}$ & $\begin{array}{l}\text { Peptidase S7 flavivirus helicase (NS3) } \\
\text { glycoside hydrolase family } 9\end{array}$ & INS \\
\hline 2060557 & 2060557 & - & INTERGENIC & Clo1313_1767 (up) & $\begin{array}{l}\text { Hypothetical protein } \\
\text { cellulosome anchoring protein cohesin } \\
\text { region }\end{array}$ & INS \\
\hline
\end{tabular}


508 To rule out the possibility that these mutations are the cause of the high-ethanol

509 yielding phenotype observed in $\Delta g \ln A$, we reconstructed the deletion again from the

510 parent strain as detailed in the Materials and Methods. We again observed a 42\%

511 increase in ethanol production compared to the $\Delta h p t$, elimination of lactate

512 production, and a decrease in $\mathrm{H}_{2}$ production (Supplementary file $5 \mathrm{~b}$ ), further

513 solidifying that deletion of $g \ln A$ is responsible for the substantial increase in ethanol

514 production.

515

516 3.4. Expression of genes involved in nitrogen metabolism increased in $\Delta g \ln A$

517 To elucidate the mechanism of increased ethanol production and decreased amino

518 acid secretion in $\Delta g \ln A$, we performed RNA-seq analysis of $\Delta g \ln A$ and the parent

519 strain on mid-exponential phase batch cultures $\left(\mathrm{OD}_{600} \sim 0.35\right)$. On average, 18.4

520 and 22.8 million reads were generated for each of the four $\Delta h p t$ and $\Delta g \ln A$

521 replicates, respectively. 3009 and 3031 genes were identified with a minimum

522 average of two reads per gene for $\Delta h p t$ and $\Delta g \ln A$, respectively (Supplementary File

523 6). Of these genes, 151 were shown to be differentially expressed by a factor $>2$ and 524 a p-value $<0.05$.

525

526 While Type I glutamine synthetase was the most highly expressed glutamine

527 synthetase (Rank 532; 5264 average reads) in $\Delta h p t$, Clo1313_1357 encoding one of

528 the three Type III glutamine synthetases was also highly expressed (Rank 634; 4410

529 average reads). The two other Type III glutamine synthetases (Clo1313_2038 and 
530 Clo1313_2303) were expressed at low levels (1256 and 25 average reads,

531 respectively) in $\Delta h p t$. However, in $\Delta g \ln A$, expression of Clo1313_2038 and

532 Clo1313_2303 increased by 13 and 77-fold, respectively. The putative pseudogene

533 Clo1313_2037, annotated as an aspartate ammonia ligase and located upstream of

534 Clo1313_2038, was also upregulated 9.7-fold. While the GOGAT encoding genes

535 (Clo1313_2030-2036) are predicted to be an operon by DOOR and Biocyc, three of

536 these subunits (Clo1313_2034-2036) increased by 19-40-fold in $\Delta g \ln A$, while

537 subunits Clo1313_2032-2033 and Clo1313_2030 increased only 1.7- to 1.9-fold.

538 Notably, Clo1313_2034-2036 were expressed at much lower levels ( 17-449

539 average reads) when compared to those of the other genes in the predicted operon

540 (2623-7082 average reads) in $\Delta h p t$. No significant change in expression was

541 observed for glutamate dehydrogenase (Clo1313_1847).

542

543 Deletion of $g \ln A$ also caused a strong increase in expression of genes involved in

544 urea uptake and metabolism. The Clo1313_2486-2499 gene cluster, encoding a

545 multi-sensor hybrid histidine kinase and a two component AraC family

546 transcriptional regulator (Clo1313_2499 and Clo1313_2498, respectively), a urea

547 binding protein (Clo1313_2497), the urea ABC transporter (Clo1313_2493-2496),

548 and urease (Clo1313_2490-2492) and urease accessory protein (Clo1313_2486-

549 2488), were upregulated 6.7 to 81 -fold in $\Delta g \ln A$. Additionally, the ammonium

550 transporter- $\mathrm{P}_{\text {II }}$ fusion (Clo1313_2260) was also upregulated by 35-fold in the

551 deletion strain.

552 
553 Two additional gene clusters were also upregulated. First, genes encoding an RNF-

554 complex (Clo1313_0061-0066) involved in electron transfer reactions between

555 ferredoxin and NADH were upregulated 1.6 to 2.9 -fold. Similarly, a gene cluster

556 (Clo1313_0073-0080) encoding a putative glycerol kinase (Clo1313_0073),

557 transketolase (Clo1313_0074-0075), alcohol dehydrogenase GroES domain protein

558 (Clo1313_0076), ABC transporter (Clo1313_0077-0079), and phosphoglycerate

559 mutase (Clo1313_0080) was also upregulated 2.4 to 3.4-fold. An increase was also

560 observed in the transcription of some genes involved in protein synthesis,

561 sporulation/germination, and a proton-translocating pyrophosphatase

562 (Supplementary File 6).

563

564 While a number of genes were down-regulated, the decrease was less pronounced

565 than the increase in gene clusters encoding genes involved in urea metabolism and

566 nitrogen assimilation. Expression of the most highly down-regulated gene

567 (Clo1313_2176), encoding a 4626 amino acid protein with an S-layer homology

568 domain (SLH), decreased 4.3-fold in $\Delta g \ln A$. Other down-regulated genes include

569 putative copper amine oxidases, genes predicted to be involved in carbohydrate

570 hydrolysis, putative fatty acid metabolism genes, and Type II excretion system

571 proteins predicted to be involved in pilus assembly (Supplementary File 6).

572

573 3.5. Intracellular glutamine levels are higher in $\Delta g \ln A$

574 Metabolomic analysis was performed to evaluate changes in metabolite pools in

$575 \Delta g \ln A$. A total of 53 metabolites were identified, including nine in which 
576 extracellular concentrations prevented accurate quantification of intracellular levels

577 (Supplementary file 7). In these cases, changes in extracellular levels are used as a

578 proxy for intracellular changes (Granucci et al., 2015; Paczia et al., 2012; Reaves et

579 al., 2013). Fourteen metabolites had significant changes relative to the parent strain.

580 Notably, glutamine levels increased 6.4-fold and extracellular $\alpha$-ketoglutarate levels

581 increased 5.5-fold in $\Delta g \ln A$, while glutamate levels remained the same. Threonine

582 and dihydroxyoorotate levels increased 7.2 and 4.9-fold, respectively. While

$583 \mathrm{NADP}^{+}$levels increased 2.6-fold, NADPH, NAD ${ }^{+}$, and NADH pools did not

584 change. GDP and GTP levels increased 2.9 and 1.8-fold respectively. Ornithine,

585 the only metabolite measured in the urea cycle, also increased 1.8-fold. Conversely,

586 the only intracellular metabolite with decreased levels in the mutant strain was

587 acetyl-CoA levels, which decreased 2.5-fold.

589 4. Discussion

590 Metabolic engineering strategies aimed at simultaneously eliminating all canonical

591 organic fermentation products, including lactate, acetate, formate, and decreased $\mathrm{H}_{2}$

592 through elimination of an $[\mathrm{FeFe}]$ hydrogenase maturation factor, have improved $C$.

593 thermocellum ethanol yields to $\sim 70 \%$ of theoretical (Papanek et al., 2015). However,

594 additional strategies are needed to redirect flux away from non-traditional

595 fermentation products such as amino acids towards ethanol. The deletion of the

596 Type I glutamine synthetase in an essentially wild type genetic background

597 described here not only reduced secreted amino acids by $44 \%$, but also improved

598 ethanol production by 53\%, suggesting that perturbation of nitrogen metabolism 
599 could be an attractive approach for the further engineering of advanced $C$.

600 thermocellum strains. Remarkably, disruption of this nitrogen assimilation gene had

601 a more significant improvement on ethanol yields than independent deletions of $l d h$

602 (Argyros et al., 2011; Biswas et al., 2014), pta (Tripathi et al., 2010) or pfl (Rydzak

603 et al., 2015).

604

605 While redirecting carbon and electron flux away from secreted amino acids towards

606 canonical fermentation products could in part explain increased ethanol yields, the

607 increase in ethanol production (approximately $10 \mathrm{mM}$ ) far exceeds the decrease in

608 amino acid secretion (approximately $1 \mathrm{mM}$ ), suggesting additional mechanisms for

609 improved ethanol yields. The increase in ethanol can potentially be explained by

610 increased NADH availability for ethanol production due to a combination of

611 increased flux through Rnf and GOGAT (Figure 3). In C. thermocellum, catabolism

612 of pyruvate to acetyl-CoA via pyruvate:ferredoxin oxidoreductase (PFOR) generates

613 reduced ferredoxin (Rydzak et al., 2014; Rydzak et al., 2009; Rydzak et al., 2012),

614 which is not a direct electron donor for ethanol production. This reduced ferredoxin

615 is typically reoxidized through either (i) $\mathrm{H}_{2}$ formation via Ech or bifurcating

616 hydrogenase, (ii) NADPH formation via NADH-dependent reduced

617 ferredoxin:NADP ${ }^{+}$oxidoreductase (NfnAB) (Rydzak et al., 2014; Wang et al.,

618 2010), or (iii) NADH formation using Rnf. Given the decrease in $\mathrm{H}_{2}$ production,

619 decrease in NADPH:NADP ${ }^{+}$ratios, and increase in Rnf expression in $\triangle g \ln A$, we

620 hypothesize that Rnf is transferring electrons from ferredoxin to produce NADH,

621 which in turn can be directly used to reduce acetyl-CoA into ethanol. While steady 
622 state ratios of NADH:NAD ${ }^{+}$did not change in $\Delta g \ln A$, levels of intracellular acetyl-

623 CoA decreased 2.5-fold, suggesting that increased electron flux to NADH from Fd

624 may accelerate acetyl-CoA reduction into ethanol.

625

626 In addition to increased ethanol production, deletion of the only annotated Type I

627 glutamine synthetase $(g \ln A)$ appears to have resulted in deregulation of nitrogen

628 metabolism. Despite the presence of excess ammonium $(28 \mathrm{mM})$ and urea $(33.3$

$629 \mathrm{mM}$ ) in the medium, genes encoding urea metabolism and transport, ammonium

630 transport, and ammonium assimilation, including GOGAT and two of the three

631 putative Type III glutamine synthetases, were highly upregulated. The upregulation

632 of urea metabolism genes presumably increased the rate of urea breakdown to

633 ammonia (and $\mathrm{CO}_{2}$ ), resulting in the higher final $\mathrm{pH}$ of $\triangle g \ln A$ when compared to

$634 \Delta h p t$ cultures. Furthermore, the upregulation of GOGAT may be responsible for the

635 observed increase of intracellular glutamine and $\alpha$-ketoglutarate levels in $\Delta g \ln A$,

636 though the cofactor specificity and in vivo directionality of GOGAT are unknown.

637 Most transamination reactions involved in amino acid synthesis use glutamate as the

638 amino donor, rather than glutamine (Reitzer, 2003), producing $\alpha$-ketoglutarate.

639 Because $\alpha$-ketoglutarate levels were 5-fold higher while intracellular glutamate

640 levels did not change in $\Delta g \ln A$, the thermodynamics of transamination would be less

641 favorable, possibly resulting in decreased rates of amino acid production.

642 Furthermore, the decrease in the $\mathrm{NADPH}$ to $\mathrm{NADP}^{+}$ratio in $\triangle g \ln A$ may also

643 decrease the free energy of NADPH-dependent anabolic amino acid reactions.

644 Together, these changes likely account for the decrease in amino acid production. 


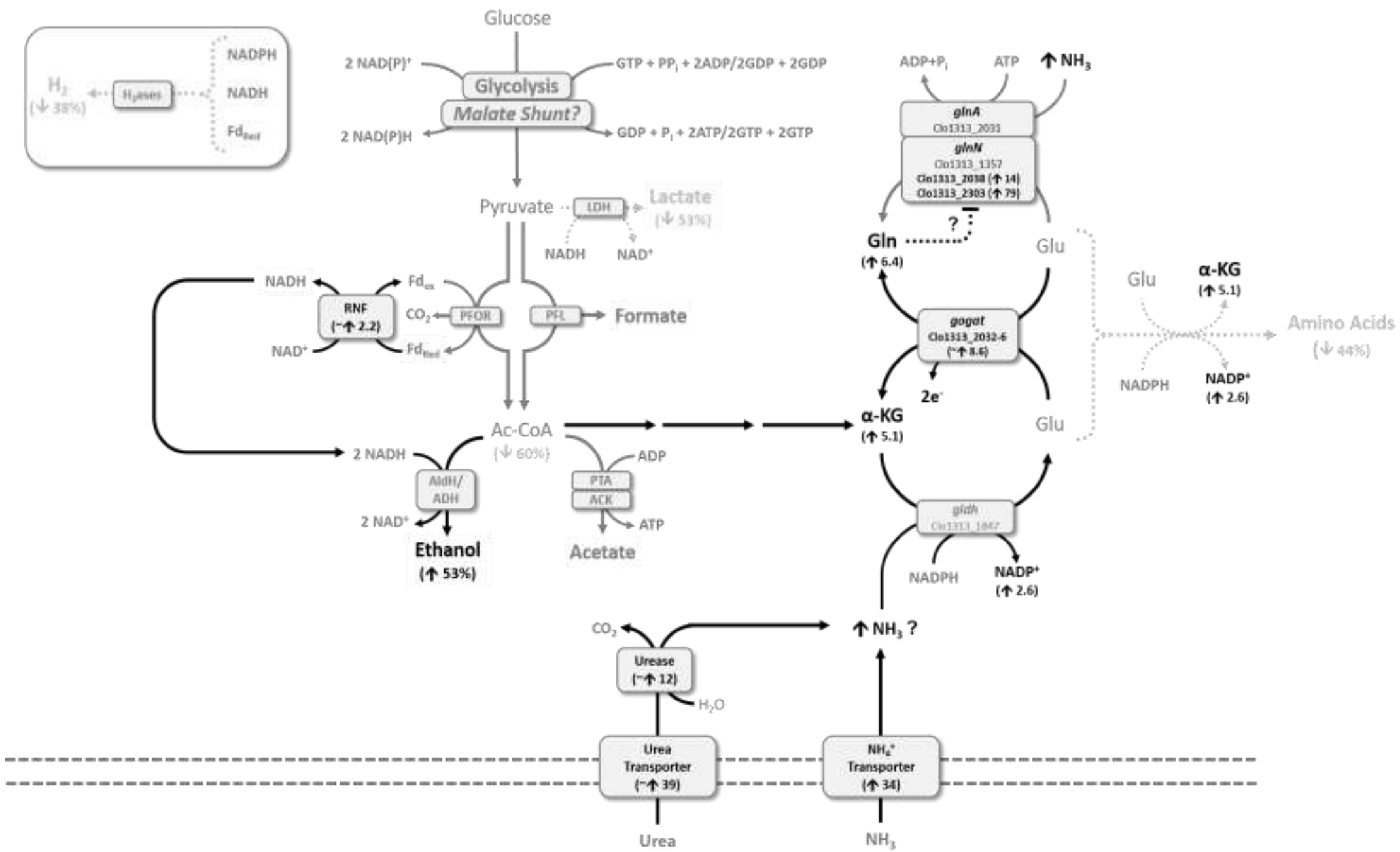

Figure 3: Proposed flux distribution in $\Delta g \ln A$ based on product profiles, transcriptomics, and metabolomic analysis. Ratios $(\Delta g \ln A / \Delta h p t)$ of product yields, transcription, and metabolite levels are provided. Black solid arrows depict a proposed increase flux while grey dotted arrows depict a proposed decrease in flux in $\Delta g \ln A$ when compared to $\Delta h p t$. 
647 Similar changes in expression of genes involved in nitrogen metabolism have been 648 observed in response to ethanol stress in C. thermocellum ATCC 27405 (Yang et al., 649 2012). Specifically, genes encoding urea transport and metabolism, two Type III 650 glutamine synthetases (Clo1313_2038, 2303), and the first 3 subunits of GOGAT 651 (Clo1313_2034-2036) were up-regulated in response to ethanol stress. However, 652 Type I glutamine synthetase and ammonium transporter- $\mathrm{P}_{\mathrm{II}}$ fusion were not 653 differentially expressed. Given that ethanol production increased in $\triangle g \ln A$, it could 654 be possible that increased ethanol concentrations may have contributed to the 655 changes in expression of nitrogen metabolism genes, but the concentration of added 656 ethanol in the previous study was substantially higher than the amount produced 657 here. The hydG deletion strain also has similarly high ethanol yields to $\Delta g \ln A$ 658 (Biswas et al., 2015) but does not show a similar transcriptomic response in 659 nitrogen-related genes (Biswas, unpublished). Furthermore, treatment of $C$.

660 thermocellum chemostat cultures with methyl viologen, which also improved

661 ethanol yields, resulted in a decrease in expression of genes encoding one of the 662 three Type III glutamine synthetases (Clo1313_2303) and GOGAT (Clo1313_2034663 2036) (Sander et al., 2015), suggesting that ethanol levels are not a major driver of 664 nitrogen assimilation genes expression.

666 With the exception of C. saccharobutylicum (Amon et al., 2010), the mechanisms 667 involved in controlling nitrogen assimilation in C. thermocellum and other 668 clostridia, are poorly understood. In C. saccharobutylicum, nitrogen assimilation is, 
669 in part, regulated by the ANTAR-family RNA-binding anti-terminator protein NitR

670 (Shu and Zhulin, 2002), which is activated by a yet unknown signal transducer

671 under nitrogen limitation (Stutz et al., 2007), and allows read-through of terminator-

672 like structures in the promoter regions of $g \ln A$ (Woods and Reid, 1995) and

673 glutamate synthase genes gltAB (Stutz et al., 2007). A unique RNA motif consisting

674 of a pair of stem-loops acts as a general recognition element of ANTAR-based

675 regulatory proteins, and has been shown through bioinformatic analysis to be

676 present upstream of the ammonium transporter-GlnK (AmtB-GlnK; Clo1313_2260)

677 in C. thermocellum (Ramesh et al., 2012). Thus, up-regulation of NitR in $C$.

678 thermocellum $\Delta g \ln A$ may increase expression of AmtB-GlnK and other proteins

679 involved in nitrogen metabolism. Furthermore, in characterized organisms, GlnK

680 senses intracellular $\alpha$-ketoglutarate levels that are typically elevated under nitrogen

681 starvation (Dodsworth et al., 2005; Radchenko et al., 2010; Yuan et al., 2009) and

682 controls a wide range of processes involved in nitrogen metabolism through protein-

683 protein interactions (Arcondeguy et al., 2001; Forchhammer, 2008; Huergo et al.,

684 2013; Sarkar et al., 2012). The increased expression of NitR and GlnK and

685 increased levels of $\alpha$-ketoglutarate likely account for the observed changes in

686 mRNA expression in the mutant strain.

687

688 In addition to $\alpha$-ketoglutarate, other effector molecules also regulate nitrogen

689 metabolism through gene expression and/or protein activity, including ammonium in

690 Actinobacteria such as Corynebacterium glutamicum (Muller et al., 2006; Nolden et

691 al., 2001; Rehm and Burkovski, 2011; Rehm et al., 2010) and glutamine in 
692 Proteobacteria (Ikeda et al., 1996; Jiang et al., 1998; Reitzer, 2003) and Firmicutes

693 such as Bacillus subtilis (Wray et al., 2001). While high $\alpha$-ketoglutarate levels in

694 the latter organisms indicate nitrogen starvation, high glutamine and low $\alpha$ -

695 ketoglutarate levels are typically indicative of nitrogen-rich conditions. In $B$.

696 subtilis, glutamine inhibits activity of glutamine synthetase (Deuel and Prusiner,

697 1974), and this feedback-inhibited form of glutamine synthetase can directly interact

698 with the global transcriptional regulator TnrA, preventing it from both binding DNA

699 and activating expression of genes involved in ammonium transport, urea

700 metabolism, and ammonium assimilation under nitrogen rich conditions (Wray et

701 al., 2001). While no TnrA homologue was identified in C. thermocellum, it is

702 feasible that another regulatory protein in C. thermocellum acts as a transcriptional

703 regulator of nitrogen metabolism genes and similarly responds to feedback-inhibited

704 glutamine synthetase. Together, the high levels of both glutamine and $\alpha$ -

705 ketoglutarate in C. thermocellum $\Delta g \ln A$ seemingly signals nitrogen-rich and -poor

706 conditions simultaneously, resulting in a transcriptional response that is indicative of

707 starvation and a flux response that suggests nitrogen excess.

708

709

710 5. Conclusion

711 While previous genetic engineering strategies were successful in improving ethanol

712 yields in $C$. thermocellum though elimination of canonical fermentation pathways,

713 ethanol yields were still too low, in part due to amino acid secretion. Deletion of the

714 Type I glutamine synthetase $(g \ln A)$ not only reduced amino acid secretion, but also 
715 increased ethanol production by $50 \%$, demonstrating that genetic manipulation of

716 nitrogen assimilation pathways is a promising strategy for improving product yields

717 in $C$. thermocellum and potentially other organisms. Deletion of $g \ln A$ increased

718 expression of nitrogen assimilation, ammonium transport, and urea uptake and

719 metabolism, despite the presence of excess nitrogen. These changes are typically

720 indicative of a nitrogen starvation response, but excess nitrogen was present during

721 growth, and that glutamine and $\alpha$-ketoglutarate levels increased, suggesting that

722 nitrogen metabolism was deregulated in response to deletion of $g \ln A$. While the

723 regulatory mechanisms behind the changes in expression and product profiles in

$724 \Delta g \ln A$ remain to be elucidated, we propose that nitrogen metabolism is regulated by

725 NitR, GlnK, and GlnA itself, while the increase in ethanol is driven by increased

726 NADH availability via Rnf. Given that deletion of $g \ln A$ resulted in a significant

727 increase in ethanol production, combining this deletion with other high-yielding $C$.

728 thermocellum strains may further improve ethanol yields.

\section{Acknowledgements}

731 We thank Kyle Sander (University of Tennessee) for running the DESeq2 program.

732 This work was supported by the BioEnergy Science Center, U.S. DOE Bioenergy

733 Research Center supported by the Office of Biological and Environmental Research

734 in the DOE Office of Science. Oak Ridge National Laboratory is managed by UT-

735 Battelle, LLC, for the U.S. DOE under contract DE-AC05-00OR22725. The

736 funders had no role in study design, data collection and analysis, decision to publish,

737 or preparation of the manuscript. 
738

739 
Figure 1: Nitrogen assimilation pathway in C. thermocellum based on genome annotation. $g \ln A$, Type I glutamine synthetase; $g \ln N$, Type III glutamine synthetase; gogat, glutamine-oxoglutarate aminotransferase/glutamate synthase type enzymes; gldh, glutamate dehydrogenase. Dashed lines indicate multiple enzyme steps.

Figure 2. Final fermentation products (A) and secreted amino acids (B) of $C$. thermocellum strains. All products were measured upon completion of cellobiose utilization. Grey bars, $\Delta h p t$; black bars, $\Delta g \ln A$; (Cys)2, cystine. Only amino acids with a change of greater than $0.08 \mathrm{mM}$ compared to $\mathrm{MTC}_{5}$ medium are shown. Only total secreted amino acid values are presented in Figure 2A. Negative values in Figure 2B indicate consumption of amino acids from the growth medium.

Figure 3: Proposed flux distribution in $\Delta g \ln A$ based on product profiles, transcriptomics, and metabolomic analysis. Ratios $(\Delta g \ln A / \Delta h p t)$ of product yields, transcription, and metabolite levels are provided. Black solid arrows depict a proposed increase flux while grey dotted arrows depict a proposed decrease in flux in $\Delta g \ln A$ when compared to $\Delta h p t$.

Supplementary File 1: Primers used to construct and sequence deletion plasmid pNJ22::2031_del, and to verify deletion of $g \ln A$ (Clo1313_2031) in $\Delta h p t$. Expected band sized in the parent strain, merodiploid, and deletion strain are provided.

\section{Supplementary file 2: Key elements of pNJ22::2031_del used for deletion of} Type I glutamine synthetases encoded by Clo1313_2031 $(\operatorname{gln} A)$. p15A ori, E. coli origin of replication; P-cbp, C. thermocellum cellobiose phosphorylase promoter; Teth39_2112 tdk, Thermoanaerobacter pseudethanolicus thymidine kinase; P-neo, neomycin phosphotransferase promoter; Neo (KanR), neomycin phosphotransferase conferring kanamycin resistance; $\mathrm{pNW} 33 \mathrm{~N}$ ori, C. thermocellum origin of replication; 2031 up, upstream sequence of homology to Clo1313_2031; 2031 down, downstream sequence of homology to Clo1313_2031; P-GapDH RBS, $C$. thermocellum glyceraldehyde-3-phosphate dehydrogenase promoter and ribosome binding site; Cat2, chloramphenicol acetyltransferase; Hpt2, hypoxanthine phosphoribosyltransferase; 2031 internal, internal sequence of homology to Clo1313_2031. Plasmid map (A) and Genbank file (B) of pNJ22::2031_del are provided.

\section{Supplementary File 3: Deletion of Clo1313_2031 $(g \ln A)$; overview and} confirmation. A) Clo1313_2031 was deleted according to the protocol outlined by Argyros et al. (2011). Primer binding sites used to amplify the locus encompassing Clo1313_2031 (P1) and internal to Clo1313_2031 (P2 and P3) and corresponding expected product sizes in the parent and mutant strain are indicated. B) PCR confirmation of Clo1313_2031 deletion. Primer set P1 amplified the chromosomal 
region that includes Clo1313_2031, and results in a 2668 bp fragment in the parent strain and a 1399 bp fragment in Clo1313_2031 deletion strain. Primer sets P2 and in the $\Delta h p t$ strain, but not in $\Delta g \ln A$. Reduction in size of the P3 amplicon and absence of P1 and P2 amplicons confirms deletion of Clo1313_2031 in the mutant strain.

\section{Supplementary File 4: Organization of genes and predicted operons involved} in nitrogen assimilation (green), ammonium transport (blue), urea metabolism (purple), and putative regulation (orange). Predicted operons are highlighted in grey.

\section{Supplementary File 5: Summary of (A) growth data and (B) fermentation and amino acid data for $\Delta h p t$, original $\Delta g \ln A$ isolate, and reconstituted $\Delta g \ln A$. \\ Product yields and carbon and electron recoveries are provided.}

Supplementary File 6: Summary of RNAseq data. Dataset contains total RNAseq reads for each gene, the strain-specific rank of expression of each gene, the mean of total normalized reads for the dataset (baseMean), standard error (IfcSE), Wald statistic (stat), $\log 2$-fold changes in expression of genes in $\triangle g \ln A$ versus the $\Delta h p t$ parent strain, Wald test $\mathrm{p}$-values, and $\mathrm{BH}$ adjusted $\mathrm{p}$-values (padj).

Supplementary File 7: Summary of metabolomic data. Dataset contains all intracellular and extracellular metabolites analyzed by GC-MS. In cases where strong metabolite signals were found extracellularly, accurate measurements of intracellular metabolites could not be achieved. Statistical significance of changes in metabolite pools was assessed using the Students $t$-test.

\section{References}

Amon, J., Titgemeyer, F., Burkovski, A., 2010. Common patterns - unique features: nitrogen metabolism and regulation in Gram-positive bacteria. Fems Microbiol Rev. 34, 588-605.

Arcondeguy, T., Jack, R., Merrick, M., 2001. P(II) signal transduction proteins, pivotal players in microbial nitrogen control. Microbiol Mol Biol Rev. 65, 80-105.

Argyros, D. A., Tripathi, S. A., Barrett, T. F., Rogers, S. R., Feinberg, L. F., Olson, D. G., Foden, J. M., Miller, B. B., Lynd, L. R., Hogsett, D. A., Caiazza, N. C., 2011. High ethanol titers from cellulose using metabolically engineered thermophilic, anaerobic microbes. Appl Environ Microbiol. 77, 8288-8294.

Arora, R., Behera, S., Kumar, S., 2015. Bioprospecting thermophilic/thermotolerant microbes for production of lignocellulosic ethanol: A future perspective. Renew Sust Energ Rev. 51, 699-717.

Biswas, R., Prabhu, S., Lynd, L. R., Guss, A. M., 2014. Increase in ethanol yield via elimination of lactate production in an ethanol-tolerant mutant of Clostridium thermocellum. PLoS One. 9, e86389.

Biswas, R., Zheng, T., Olson, D. G., Lynd, L. R., Guss, A. M., 2015. Elimination of hydrogenase active site assembly blocks $\mathrm{H} 2$ production and increases ethanol yield in Clostridium thermocellum. Biotechnol Biofuels. 8. 
Bogdahn, M., Kleiner, D., 1986. Inorganic nitrogen-metabolism in 2 cellulose-degrading Clostridia. Archives of Microbiology. 145, 159-161.

Carere, C. R., Rydzak, T., Cicek, N., Levin, D. B., Sparling, R., 2014. Role of transcription and enzyme activities in redistribution of carbon and electron flux in response to $\mathrm{N}(2)$ and $\mathrm{H}(2)$ sparging of open-batch cultures of Clostridium thermocellum ATCC 27405. Appl Microbiol Biotechnol. 98, 2829-40.

Chen, K., Wallis, J. W., McLellan, M. D., Larson, D. E., Kalicki, J. M., Pohl, C. S., McGrath, S. D., Wendl, M. C., Zhang, Q., Locke, D. P., Shi, X., Fulton, R. S., Ley, T. J., Wilson, R. K., Ding, L., Mardis, E. R., 2009. BreakDancer: an algorithm for high-resolution mapping of genomic structural variation. Nat Methods. 6, 677-81.

Clasquin, M. F., Melamud, E., Rabinowitz, J. D., 2012. LC-MS data processing with MAVEN: a metabolomic analysis and visualization engine. Curr Protoc Bioinformatics. vol. 37. John Wiley \& Sons, Inc., pp. 14.11.1-14.11.23.

Dam, P., Olman, V., Harris, K., Su, Z. C., Xu, Y., 2007. Operon prediction using both genome-specific and general genomic information. Nucleic Acids Res. 35, 288-298.

Deng, Y., Olson, D. G., Zhou, J., Herring, C. D., Joe Shaw, A., Lynd, L. R., 2013. Redirecting carbon flux through exogenous pyruvate kinase to achieve high ethanol yields in Clostridium thermocellum. Metab Eng. 15, 151-8.

Desvaux, M., Guedon, E., Petitdemange, H., 2001a. Carbon flux distribution and kinetics of cellulose fermentation in steady-state continuous cultures of Clostridium cellulolyticum on a chemically defined medium. J Bacteriol. 183, 119-130.

Desvaux, M., Guedon, E., Petitdemange, H., 2001b. Kinetics and metabolism of cellulose degradation at high substrate concentrations in steady-state continuous cultures of Clostridium cellulolyticum on a chemically defined medium. Appl Environ Microbiol. 67, 3837-3845.

Desvaux, M., Guedon, E., Petitdemange, H., 2001c. Metabolic flux in cellulose batch and cellulose-fed continuous cultures of Clostridium cellulolyticum in response to acidic environment. Microbiol-Sgm. 147, 1461-1471.

Deuel, T. F., Prusiner, S., 1974. Regulation of glutamine-synthetase from Bacillus subtilis by divalent cations, feedback inhibitors, and L-glutamine. J Biol Chem. 249, 257264.

Dodsworth, J. A., Cady, N. C., Leigh, J. A., 2005. 2-Oxoglutarate and the PII homologues NifI1 and NifI2 regulate nitrogenase activity in cell extracts of Methanococcus maripaludis. Mol Microbiol. 56, 1527-38.

Ellis, L. D., Holwerda, E. K., Hogsett, D., Rogers, S., Shao, X., Tschaplinski, T., Thorne, P., Lynd, L. R., 2012. Closing the carbon balance for fermentation by Clostridium thermocellum (ATCC 27405). Bioresource Technol. 103, 293-9.

Forchhammer, K., 2008. P-II signal transducers: novel functional and structural insights. Trends Microbiol. 16, 65-72.

Gowen, C. M., Fong, S. S., 2010. Genome-scale metabolic model integrated with RNAseq data to identify metabolic states of Clostridium thermocellum. Biotechnol J. 5, 759767.

Granucci, N., Pinu, F. R., Han, T. L., Villas-Boas, S. G., 2015. Can we predict the intracellular metabolic state of a cell based on extracellular metabolite data? Mol Biosyst. 11, 3297-304.

Groom, J., Chung, D., Olson, D. G., Lynd, L. R., Guss, A. M., Westpheling, J., 2016. Promiscuous plasmid replication in thermophiles: Use of a novel hyperthermophilic replicon for genetic manipulation of Clostridium thermocellum at its optimum growth temperature. Metabolic Engineering Communications. 3, 30-38. 
Guedon, E., Payot, S., Desvaux, M., Petitdemange, H., 1999. Carbon and electron flow in Clostridium cellulolyticum grown in chemostat culture on synthetic medium. J Bacteriol. 181, 3262-3269.

Guss, A. M., Olson, D. G., Caiazza, N. C., Lynd, L. R., 2012. Dcm methylation is detrimental to plasmid transformation in Clostridium thermocellum. Biotechnol Biofuels. 5, 30.

Harris, R. F., Adams, S. S., 1979. Determination of the carbon-bound electron composition of microbial cells and metabolites by dichromate oxidation. Appl Environ Microbiol. 37, 237-43.

Herring, C. D., Kenealy, W. R., Shaw, A. J., Covalla, S. F., Olson, D. G., Zhang, J. Y., Sillers, W. R., Tsakraklides, V., Bardsley, J. S., Rogers, S. R., Thorne, P. G., Johnson, J. P., Foster, A., Shikhare, I. D., Klingeman, D. M., Brown, S. D., Davison, B. H., Lynd, L. R., Hogsett, D. A., 2016. Strain and bioprocess improvement of a thermophilic anaerobe for the production of ethanol from wood. Biotechnol Biofuels. 9.

Himmel, M. E., Ding, S. Y., Johnson, D. K., Adney, W. S., Nimlos, M. R., Brady, J. W., Foust, T. D., 2007. Biomass recalcitrance: engineering plants and enzymes for biofuels production. Science. 315, 804-7.

Holwerda, E. K., Hirst, K. D., Lynd, L. R., 2012. A defined growth medium with very low background carbon for culturing Clostridium thermocellum. J Ind Microbiol Biotechnol. 39, 943-7.

Holwerda, E. K., Thorne, P. G., Olson, D. G., Amador-Noguez, D., Engle, N. L., Tschaplinski, T. J., van Dijken, J. P., Lynd, L. R., 2014. The exometabolome of Clostridium thermocellum reveals overflow metabolism at high cellulose loading. Biotechnol Biofuels. 7, 155.

Huergo, L. F., Chandra, G., Merrick, M., 2013. P(II) signal transduction proteins: nitrogen regulation and beyond. Fems Microbiol Rev. 37, 251-83.

Ikeda, T. P., Shauger, A. E., Kustu, S., 1996. Salmonella typhimurium apparently perceives external nitrogen limitation as internal glutamine limitation. J Mol Biol. 259, 589607.

Jiang, P., Peliska, J. A., Ninfa, A. J., 1998. The regulation of Escherichia coli glutamine synthetase revisited: role of 2-ketoglutarate in the regulation of glutamine synthetase adenylylation state. Biochemistry-Us. 37, 12802-10.

Karp, P. D., 2005. BioCyc pathway database collection and the pathway tools software. Abstr Pap Am Chem S. 229, U1178-U1178.

Kridelbaugh, D. M., Nelson, J., Engle, N. L., Tschaplinski, T. J., Graham, D. E., 2013. Nitrogen and sulfur requirements for Clostridium thermocellum and Caldicellulosiruptor bescii on cellulosic substrates in minimal nutrient media. Bioresour Technol. 130, 125-35.

Lamed, R., Zeikus, J. G., 1980. Ethanol production by thermophilic bacteria: relationship between fermentation product yields of and catabolic enzyme activities in Clostridium thermocellum and Thermoanaerobium brockii. J Bacteriol. 144, 56978.

Li, H., Durbin, R., 2009. Fast and accurate short read alignment with Burrows-Wheeler transform. Bioinformatics. 25, 1754-1760.

Li, H., Handsaker, B., Wysoker, A., Fennell, T., Ruan, J., Homer, N., Marth, G., Abecasis, G., Durbin, R., Genome Project Data Processing, S., 2009. The Sequence Alignment/Map format and SAMtools. Bioinformatics. 25, 2078-9.

Lin, W. R., Peng, Y., Lew, S., Lee, C. C., Hsu, J. J., Hamel, J. F., Demain, A. L., 1998. Purification and characterization of acetate kinase from Clostridium thermocellum. Tetrahedron. 54, 15915-15925. 
Love, M. I., Huber, W., Anders, S., 2014. Moderated estimation of fold change and dispersion for RNA-seq data with DESeq2. Genome Biol. 15.

Lynd, L. R., van Zyl, W. H., McBride, J. E., Laser, M., 2005. Consolidated bioprocessing of cellulosic biomass: an update. Curr Opin Biotechnol. 16, 577-83.

Lynd, L. R., Weimer, P. J., van Zyl, W. H., Pretorius, I. S., 2002. Microbial cellulose utilization: fundamentals and biotechnology. Microbiol Mol Biol R. 66, 506-77.

Magasanik, B., 1996. Regulation of nitrogen utilization. In: Neidhardt, F. C., Curtiss, R., Ingraham, J. L., Lin, E. C. C., Low, K. B., Magasanik, B., Reznikoff, W. S., Riley, M., Schaechter, M., Umbarger, H. E., Eds.), Escherichia coli and Salmonella: Cellular and Molecular Biology. ASM Press, Washington, DC, pp. 1344-1356.

Mao, F., Dam, P., Chou, J., Olman, V., Xu, Y., 2009. DOOR: a database for prokaryotic operons. Nucleic Acids Res. 37, D459-63.

Melamud, E., Vastag, L., Rabinowitz, J. D., 2010. Metabolomic analysis and visualization engine for LC-MS data. Anal Chem. 82, 9818-9826.

Moat, A. G., Foster, J. W., Spector, M. P., 2002. Microbial Physiology (4th ed.). Wiley-Liss Inc., New York.

Mohr, G., Hong, W., Zhang, J., Cui, G. Z., Yang, Y., Cui, Q., Liu, Y. J., Lambowitz, A. M., 2013. A targetron system for gene targeting in thermophiles and its application in Clostridium thermocellum. PLoS One. 8, e69032.

Muller, T., Strosser, J., Buchinger, S., Nolden, L., Wirtz, A., Kramer, R., Burkovski, A., 2006. Mutation-induced metabolite pool alterations in Corynebacterium glutamicum: Towards the identification of nitrogen control signals. J Biotechnol. 126, 440-453.

Nolden, L., Ngouoto-Nkili, C. E., Bendt, A. K., Kramer, R., Burkovski, A., 2001. Sensing nitrogen limitation in Corynebacterium glutamicum: the role of $g \ln K$ and $g \ln D$. Mol Microbiol. 42, 1281-1295.

Olson, D. G., Lynd, L. R., 2012. Transformation of Clostridium thermocellum by electroporation. Method Enzymol. 510, 317-30.

Olson, D. G., Maloney, M., Lanahan, A. A., Hon, S., Hauser, L. J., Lynd, L. R., 2015. Identifying promoters for gene expression in Clostridium thermocellum. Metabolic Engineering Communications. 2, 23-29.

Paczia, N., Nilgen, A., Lehmann, T., Gatgens, J., Wiechert, W., Noack, S., 2012. Extensive exometabolome analysis reveals extended overflow metabolism in various microorganisms. Microbial cell factories. 11, 122.

Panesar, P. S., Marwaha, S. S., Kennedy, J. F., 2006. Zymomonas mobilis: an alternative ethanol producer. J Chem Technol Biot. 81, 623-635.

Papanek, B., Biswas, R., Rydzak, T., Guss, A. M., 2015. Elimination of metabolic pathways to all traditional fermentation products increases ethanol yields in Clostridium thermocellum. Metab Eng. 32, 49-54.

Paye, J. M. D., Guseva, A., Hammer, S., Davis, M., Gjersing, E., Pattathil, S., Davison, B., Hahn, M., Lynd, L. R., 2015. Biological lignocellulose solubilization: Comparative evaluation of biocatalysts and enhancement via cotreatment. Biotechnol Biofuels. In press.

Radchenko, M. V., Thornton, J., Merrick, M., 2010. Control of AmtB-GlnK complex formation by intracellular levels of ATP, ADP, and 2-oxoglutarate. J Biol Chem. 285, 31037-45.

Raman, B., McKeown, C. K., Rodriguez, M., Jr., Brown, S. D., Mielenz, J. R., 2011. Transcriptomic analysis of Clostridium thermocellum ATCC 27405 cellulose fermentation. BMC Microbiol. 11, 134.

Raman, B., Pan, C., Hurst, G. B., Rodriguez, M., Jr., McKeown, C. K., Lankford, P. K., Samatova, N. F., Mielenz, J. R., 2009. Impact of pretreated Switchgrass and 
1016

1017

1018

1019

1020

1021

1022

1023

1024

1025

1026

1027

1028

1029

1030

1031

1032

1033 biomass carbohydrates on Clostridium thermocellum ATCC 27405 cellulosome composition: a quantitative proteomic analysis. PLoS One. 4, e5271.

Ramesh, A., DebRoy, S., Goodson, J. R., Fox, K. A., Faz, H., Garsin, D. A., Winkler, W. C., 2012. The mechanism for RNA recognition by ANTAR regulators of gene expression. Plos Genet. 8.

Reaves, M. L., Young, B. D., Hosios, A. M., Xu, Y. F., Rabinowitz, J. D., 2013. Pyrimidine homeostasis is accomplished by directed overflow metabolism. Nature. 500, 23741.

Rehm, N., Burkovski, A., 2011. Engineering of nitrogen metabolism and its regulation in Corynebacterium glutamicum: influence on amino acid pools and production. Appl Microbiol Biot. 89, 239-248.

Rehm, N., Georgi, T., Hiery, E., Degner, U., Schmiedl, A., Burkovski, A., Bott, M., 2010. L-Glutamine as a nitrogen source for Corynebacterium glutamicum: derepression of the AmtR regulon and implications for nitrogen sensing. Microbiol-Sgm. 156, 3180-3193.

Reitzer, L., 2003. Nitrogen assimilation and global regulation in Escherichia coli. Annu Rev Microbiol. 57, 155-176.

Romero, P. R., Karp, P. D., 2004. Using functional and organizational information to improve genome-wide computational prediction of transcription units on pathwaygenome databases. Bioinformatics. 20, 709-U342.

Rydzak, T., Grigoryan, M., Cunningham, Z. J., Krokhin, O. V., Ezzati, P., Cicek, N., Levin, D. B., Wilkins, J. A., Sparling, R., 2014. Insights into electron flux through manipulation of fermentation conditions and assessment of protein expression profiles in Clostridium thermocellum. Appl Microbiol Biotechnol. 98, 6497-510.

Rydzak, T., Levin, D. B., Cicek, N., Sparling, R., 2009. Growth phase-dependant enzyme profile of pyruvate catabolism and end-product formation in Clostridium thermocellum ATCC 27405. J Biotechnol. 140, 169-75.

Rydzak, T., Lynd, L., Guss, A., 2015. Elimination of formate production in Clostridium thermocellum. J Ind Microbiol Biot.

Rydzak, T., McQueen, P. D., Krokhin, O. V., Spicer, V., Ezzati, P., Dwivedi, R. C., Shamshurin, D., Levin, D. B., Wilkins, J. A., Sparling, R., 2012. Proteomic analysis of Clostridium thermocellum core metabolism: relative protein expression profiles and growth phase-dependent changes in protein expression. BMC Microbiol. 12, 214.

Sander, K., Wilson, C. M., Rodriguez, M., Jr., Klingeman, D. M., Rydzak, T., Davison, B. H., Brown, S. D., 2015. Clostridium thermocellum DSM 1313 transcriptional responses to redox perturbation. Biotechnol Biofuels. 8, 211.

Sarkar, A., Kohler, J., Hurek, T., Reinhold-Hurek, B., 2012. A novel regulatory role of the Rnf complex of Azoarcus sp strain BH72. Mol Microbiol. 83, 408-422.

Shimizu, K., 2013. Metabolic regulation of a bacterial cell system with emphasis on Escherichia coli metabolism. ISRN Biochem. 2013, 645983.

Shu, C. Y. J., Zhulin, I. B., 2002. ANTAR: an RNA-binding domain in transcription antitermination regulatory proteins. Trends Biochem Sci. 27, 3-5.

Sparling, R., Islam, R., Cicek, N., Carere, C., Chow, H., Levin, D. B., 2006. Formate synthesis by Clostridium thermocellum during anaerobic fermentation. Can J Microbiol. 52, 681-8.

Stutz, H. E., Ouixley, K. W. M., McMaster, L. D., Reid, S. J., 2007. Co-regulation of the nitrogen-assimilatory gene cluster in Clostridium saccharobutylicum. MicrobiolSgm. 153, 3081-3090.

Taillefer, M., Rydzak, T., Levin, D. B., Oresnik, I. J., Sparling, R., 2015. Reassesment of the transhydrogenase 'Malate Shunt' in Clostridium thermocellum ATCC 27405 
through kinetic characterization of malic enzyme and malate dehydrogenase. Appl Environ Microbiol.

Tian, L., Papanek, B., Olson, D. G., Rydzak, T., Holwerda, E. K., Zheng, T., Zhou, J., Maloney, M., Jiang, N., Giannone, R. J., Hettich, R. L., Guss, A. M., Lynd, L. R., 2016. Simultaneous achievement of high ethanol yield and titer in Clostridium thermocellum. Biotechnol Biofuels. 9, 116.

Tripathi, S. A., Olson, D. G., Argyros, D. A., Miller, B. B., Barrett, T. F., Murphy, D. M., McCool, J. D., Warner, A. K., Rajgarhia, V. B., Lynd, L. R., Hogsett, D. A., Caiazza, N. C., 2010. Development of pyrF-based genetic system for targeted gene deletion in Clostridium thermocellum and creation of a pta mutant. Appl Environ Microbiol. 76, 6591-9.

Tyurin, M. V., Desai, S. G., Lynd, L. R., 2004. Electrotransformation of Clostridium thermocellum. Appl Environ Microbiol. 70, 883-90.

van der Veen, D., Lo, J., Brown, S. D., Johnson, C. M., Tschaplinski, T. J., Martin, M., Engle, N. L., van den Berg, R. A., Argyros, A. D., Caiazza, N. C., Guss, A. M., Lynd, L. R., 2013. Characterization of Clostridium thermocellum strains with disrupted fermentation end-product pathways. J Ind Microbiol Biot. 40, 725-34.

van Rooyen, J., Belrhali, H., Abratt, V., Sewell, B. T., 2011. Proteolysis of the type III glutamine synthetase from Bacteroides fragilis causes expedient crystal-packing rearrangements. Acta Crystallogr Sect F Struct Biol Cryst Commun. 67, 358-63.

Vohra, M., Manwar, J., Manmode, R., Padgilwar, S., Patil, S., 2014. Bioethanol production: Feedstock and current technologies. Journal of Environmental Chemical Engineering. 2, 573-584.

Wang, M., Han, J., Dunn, J. B., Cai, H., Elgowainy, A., 2012. Well-to-wheels energy use and greenhouse gas emissions of ethanol from corn, sugarcane and cellulosic biomass for US use. Environ Res Lett. 7.

Wang, S., Huang, H., Moll, J., Thauer, R. K., 2010. NADP+ reduction with reduced ferredoxin and NADP+ reduction with NADH are coupled via an electronbifurcating enzyme complex in Clostridium kluyveri. J Bacteriol. 192, 5115-23.

Wilson, C. M., Yang, S., Rodriguez, M., Jr., Ma, Q., Johnson, C. M., Dice, L., Xu, Y., Brown, S. D., 2013. Clostridium thermocellum transcriptomic profiles after exposure to furfural or heat stress. Biotechnol Biofuels. 6, 131.

Woods, D. R., Reid, S. J., 1995. Regulation of nitrogen-metabolism, starch utilization and the Beta-Hbd-Adhl gene cluster in Clostridium acetobutylicum. Fems Microbiol Rev. 17, 299-306.

Wray, L. V., Jr., Ferson, A. E., Rohrer, K., Fisher, S. H., 1996. TnrA, a transcription factor required for global nitrogen regulation in Bacillus subtilis. Proc Natl Acad Sci U S A. 93, 8841-5.

Wray, L. V., Jr., Zalieckas, J. M., Fisher, S. H., 2001. Bacillus subtilis glutamine synthetase controls gene expression through a protein-protein interaction with transcription factor TnrA. Cell. 107, 427-35.

Yang, S., Giannone, R. J., Dice, L., Yang, Z. K., Engle, N. L., Tschaplinski, T. J., Hettich, R. L., Brown, S. D., 2012. Clostridium thermocellum ATCC27405 transcriptomic, metabolomic and proteomic profiles after ethanol stress. BMC Genomics. 13, 336.

Yuan, J., Doucette, C. D., Fowler, W. U., Feng, X. J., Piazza, M., Rabitz, H. A., Wingreen, N. S., Rabinowitz, J. D., 2009. Metabolomics-driven quantitative analysis of ammonia assimilation in E. coli. Mol Syst Biol. 5, 302.

Zhou, J., Olson, D. G., Argyros, D. A., Deng, Y., van Gulik, W. M., van Dijken, J. P., Lynd, L. R., 2013. Atypical glycolysis in Clostridium thermocellum. Appl Environ Microbiol. 79, 3000-8. 
1088

1089 Websites:

1090

1091

1092

1093

1094

1095

1096
Zimmer, D. P., Soupene, E., Lee, H. L., Wendisch, V. F., Khodursky, A. B., Peter, B. J., Bender, R. A., Kustu, S., 2000. Nitrogen regulatory protein C-controlled genes of Escherichia coli: scavenging as a defense against nitrogen limitation. Proc Natl Acad Sci U S A. 97, 14674-9.
RFA (Renewable Fuels Association), 2016. World fuel ethanol production.

http://www.ethanolrfa.org/resources/industry/statistics/ (accessed June 30, 2016).

DEFRA (Department for Environment, Food, and Rural Affairs), 2008. The role of demand for biofuel in the agricultural commodity price spikes of 2007/08.

globalrfa.org/file_download/9 (accessed April 25, 2016). 